\title{
Kinetic Modeling of Multiple Adsorption of Heavy Metal lons Using Activated Carbon from Nigerian Bamboo for Design of Adsorbers
}

\author{
Ademiluyi Falilat Taiwo \\ Department of Chemical/Petrochemical Engineering, Faculty of Engineering, Rivers State University of Science and Technology, Nkpolu, \\ Port Harcourt, Nigeria
}

Email address:

ademuluyi@yahoo.com, ademiluyi.taiwo2@gmail.com

\section{To cite this article:}

Ademiluyi Falilat Taiwo, Kinetic Modeling of Multiple Adsorption of Heavy Metal Ions Using Activated Carbon from Nigerian Bamboo for Design of Adsorbers. American Journal of Chemical Engineering. Vol. 4, No. 5, 2016, pp. 105-113. doi: 10.11648/j.ajche.20160405.13

Received: August 30, 2016; Accepted: September 10, 2016; Published: October 11, 2016

\begin{abstract}
In this study, the kinetics modeling for design of adsorbers for multiple adsorption of heavy metal ions was carried out using activated carbon from waste Nigerian bamboo. The bamboo was cut into sizes, washed, dried and was carbonized at $350^{\circ} \mathrm{C}-500^{\circ} \mathrm{C}$. It was then activated at $800^{\circ} \mathrm{C}$ using nitric acid. Simultaneous batch adsorption of different heavy metal ions $\left(\mathrm{Cd}^{2+}, \mathrm{Ni}^{2+}, \mathrm{Pb}^{2+}, \mathrm{Cr}^{3+}, \mathrm{Cu}^{2+}\right.$ and $\left.\mathrm{Zn}^{2+}\right)$ in same aqueous solution using activated carbon from Nigerian bamboo was carried out at different initial concentration till equilibrium was reached. In order to determine the mechanism of sorption for multiple adsorption of these heavy metals ions, the kinetic data were modeled using the pseudo first order, pseudo second order kinetic equations, and intra-particle diffusion models. The pseudo first order did not fit well into the kinetic data. The pseudo second order equation was the best applicable model to describe the sorption process. Hence the pseudo second order kinetic reaction is the rate controlling step with some intra particle diffusion taking place. An empirical model was also developed which can then be used for predicting and designing adsorber for the multiple removal of $99 \%$ heavy metal ions at any given initial heavy metal ions concentration and the adsorption time required for any multi-stage adsorption system using Nigerian Bamboo activated carbon.
\end{abstract}

Keywords: Nigerian Bamboo, Activated Carbon, Heavy Metal Ions, Multiple Adsorption, Kinetics, Adsorber Design

\section{Introduction}

One of the most challenging task in water treatment is simultaneous removal of multi-metal ions in solution. Sourcing for a cheap and effective local adsorbent that can selectively adsorbed several heavy metals ions such as cadmium, nickel, lead, chromium, copper, zinc ions (i.e $\mathrm{Cd}^{2+}$, $\mathrm{Ni}^{2+}, \mathrm{Pb}^{2+}, \mathrm{Cr}^{3+}, \mathrm{Cu}^{2+}$ and $\left.\mathrm{Zn}^{2+}\right)$ often found in industrial and refinery waste waters in same solution is important for Nigeria, since the removal of heavy metals ions in solution to acceptable limit nontoxic to the ecosystem is still a challenge. Many works on adsorption has been carried out using Stirred batch adsorbers [1-3]. In the removal of chromium(VI) using magnetically modified graphene oxide-chitosan composite, a single stage batch adsorber was proposed for removal of $\mathrm{Cr}(\mathrm{VI})$ concentration up to $0.05 \mathrm{mg} \mathrm{L}^{-1}$ [2] while for the removal of $\mathrm{Cu}$ (II) from aqueous solutions when clay of the
Gulbarga region, Karnataka, India was used as an adsorbent, a two-stage batch adsorber was designed for the removal of $\mathrm{Cu}$ (II) from aqueous solutions, which reduced the adsorbent dose by $51 \%$ when compared to that of a single-stage adsorption system [3]. Stirred batch adsorbers are often used in adsorption studied because they offer a number of advantages in comparison to fixed bed systems, as they reduce mass transfer resistances, pressure drops and fouling of the sorbent particles [4]. Minimizing the contact time for a fixed percentage of pollution removal using a fixed mass of adsorbent will result in being able to process more batches of polluted wastewater per day, thus enabling the required treatment plant items to be reduced in size, with a decrease in the plant capital cost.

Many studies have been carried out on heavy metal ions adsorption using many adsorbent [5-9]. Recent studies showed that Nigerian Bamboo activated with Nitric acid is 
very effective for the multiple adsorption of heavy metal ions in water [10-11]. In these studies the kinetics of the multiple metal ions adsorption using Nigerian bamboo carbon was not studied. Also the amount of adsorbent/volume of adsorbate required for the sorption process, the number of stages required and the contact time of adsorbate and adsorbent was not considered These are important parameters that should be considered in order to understand the sorption process and design of adsorbers for multiple adsorption of these heavy metal ions in waste waters.

Therefore, the objectives of this paper was to study the kinetics of modelling the multiple adsorption of heavy metal ions for the design batch adsorbers.

\section{Materials and Methods}

\subsection{Materials}

The following materials and apparatus were used for this work: waste Nigerian based bamboo, Nitric acid was used as activating agents, A pyrolytic reactor was used for carbonization of the bamboo with condenser to condense other by products of the pyrolysis process. Other materials used are desiccators, crucibles, funnels, and filter papers. Two electronic weighing balance, Ohaus top loading balance $( \pm 0.01)$ was used to weigh the bamboo before pyrolysis, while a more sensitive electronic analytical weighing balance ( \pm 0.001 , Adams AFP $360 \mathrm{~L})$ was used for other analysis, retort stand, thermocouple with temperature sensor, spatula, crusher, sieves, measuring cylinders, and petri dishes etc.

\subsection{Methods}

\subsubsection{Preparation of Bamboo Samples}

Waste Bamboos were obtained from a construction site in the University. The Bamboos was cut into small sizes of about $2 \mathrm{~cm}$ long with a cutting machine. They were washed thoroughly with distilled water to remove all the adherent extraneous matter and dried in the oven.

\subsubsection{Carbonization Process}

Two kilogram $(2 \mathrm{~kg})$ of the dried Bamboo pieces were weighed into a pyrolysis reactor and was pyrolysed between $\left(350-450^{\circ} \mathrm{C}\right)$ in the absence of air for two hours, 30 minutes. A condenser was connected to the pyrolysis unit to cool down the vapour so as to monitor the rate at which the distillate was formed during the pyrolysis. The carbonization process was terminated when there is no distillate passing through the condenser. The carbonized material was then cooled to room temperature and kept in a dry container.

\subsubsection{Chemical Activation}

The carbonized bamboo was crushed and screened using $1.18 \mathrm{~mm}$ sieve in order to get a uniform size of the particle. The bamboo was activated with Nitric acid of known concentration. Nitric acid was found to be the best for metal ion adsorption and so was used as previously reported [12]. $100 \mathrm{~g}$ of carbonized bamboo was carefully weighed mixed with $150 \mathrm{~cm}^{3}$ of Nitric acid, stirred until the mixture formed a paste. The paste was dried in an oven to reduce the moisture content before further activation in the furnace with several crucibles. The crucibles were then transferred into a muffle furnace where it was heated for 1hour at a temperature of $800^{\circ} \mathrm{C}$ in the absence of air so as to increase the surface area of the carbon. The activated carbon was cooled at room temperature and washed with distilled water until the $\mathrm{pH}$ value was approximately 7 , with no trace of nitric acid. The activated carbon was then dried and the final products were kept in an air tight containers.

\subsubsection{Characterization of Activated Carbon Produced}

The activated carbon produced from Nigerian Bamboo was characterized to determine properties of the carbon such as bulk density, pore volume, percentage burnt off, moisture content, ash content, particle size, benzene adsorption, methylene blue and iodine number [10].

\subsubsection{Determination of Adsorption Capacity}

Six metallic salts containing metal ions $\left(\mathrm{Cd}^{2+}, \mathrm{Ni}^{2+}, \mathrm{Pb}^{2+}\right.$, $\mathrm{Cr}^{2+}, \mathrm{Cu}^{2+}$ and $\mathrm{Zn}^{2+}$ ) often found in industrial waste waters especially refineries were used for this study. The metallic salts were used to produce different concentrations of these heavy metals ions in solution. Batch adsorption of the six metal ions using the activated carbon was carried out in the same aqueous solution for the different concentrations of these heavy metals ions in solution i.e. $100 \mathrm{ml}$ of the six metal ions in same solution: $1 \mathrm{~g}$ of activated carbon. The samples were stirred, and batch adsorption was carried out for 30,45 , 90, 120, 240 and 990 minutes till equilibration. The samples were filtered out with filter papers to remove any carbon particles after each adsorption. $5 \mathrm{mls}$ of the resulting filtrate after adsorption was diluted with $50 \mathrm{ml}$ of $2 \%$ nitric acid for digestion and metals ions in filtrate after digestion were analyzed using Atomic Absorption Spectrophotometer (AAS).

\subsubsection{Metal Uptake}

The amount of metal adsorbed per unit weight of adsorbent, $\mathrm{Q}_{\mathrm{e}}(\mathrm{mg} / \mathrm{g})$, was calculated from equation 1 [13].

$$
\mathrm{Q}_{\mathrm{e}}=\frac{\left(\mathrm{C}_{\mathrm{o}}-\mathrm{C}_{\mathrm{e}}\right) \mathrm{V}}{M}
$$

where: $\mathrm{C}_{\mathrm{o}}=$ The initial metal concentration in liquid phase $\left(\mathrm{mgL}^{-1}\right)$

$\mathrm{C}_{\mathrm{e}}=$ The liquid phase metal concentration at equilibrium $\left(\mathrm{mg} \mathrm{L}^{-1}\right)$

$\mathrm{V}=$ The volume of metal solution used $(\mathrm{L})$

$\mathrm{M}=$ The mass of adsorbent used $(\mathrm{g})$

\subsubsection{Kinetic Study}

Three kinetic models were used in this study to model the adsorption of heavy metal ions on bamboo activated carbon namely: pseudo first order, pseudo second order and the intra particle diffusion models.

a) The pseudo first order considers the rate of occupation of adsorption sites to be proportional to the number of 
unoccupied sites.

$$
\ln \left(Q_{e}-\mathrm{Q}_{t}\right)=\ln Q_{e}-k_{l} \mathrm{t}
$$

where, $\mathrm{Q}_{e}$ is the mass of metal adsorbed at equilibrium $(\mathrm{mg} / \mathrm{g}), Q_{t}(\mathrm{mg} / \mathrm{g})$ is the mass of metal adsorbed at time $t$ and $k_{l}$ is the first order reaction rate constant $(\mathrm{L} / \mathrm{min})$. A straight line of $\ln \left(Q_{e}-Q_{t}\right)$ verses $t$ indicates the application of the first order kinetic model.

b) The Pseudo Second order kinetic model for adsorption of heavy metal ions is expressed as [13]:

$$
\frac{t}{Q_{t}}=\frac{1}{k_{2} Q_{e}^{2}}+\frac{t}{Q_{e}}
$$

Intra -particle diffusion may be the rate determining step in batch adsorption process the uptake of adsorbate varies with the square root of the adsorption time [14]. So that

$$
\mathrm{Q}_{\mathrm{t}}=\mathrm{k}_{2} \mathrm{t}^{0.5}+\mathrm{C}
$$

A linear plot of $Q_{t}$ versus $t^{0.5}$ shows that the adsorption mechanism follows intra -particle diffusion and if the intra particle diffusion is the rate controlling step, the line would passes through the origin.

\section{Results and Discussion}

\subsection{Sorption Kinetics of the Multiple Adsorption of These Heavy Metal Ions in Aqueous Solution Using Activated Carbon from Nigerian Bamboo}

In order to understand the possible mechanism for the adsorption of the multiple adsorption of these heavy metal ions in aqueous solution the pseudo first order kinetic model, pseudo second order kinetic model and the intraparticle diffusion kinetic model were used for the sorption kinetic analysis. Figures 1-3 shows the pseudo first, second order kinetic model plot as well as the intraparticle diffusion model plot for multiple adsorption of heavy metal ions same solution using activated carbon from Nigerian bamboo at $28^{\circ} \mathrm{C}$. The trend of the plots are similar to that reported earlier for single metal adsorption. The amount of metal ions adsorbed increase generally with time. Selective adsorption is still exhibited by bamboo activated carbon for the different metal ions in solution with more affinity for lead and cadmium. The linearity of the three plot shows that the adsorption mechanism is not only taken place at surface but combined with diffusion and chemisorptions.

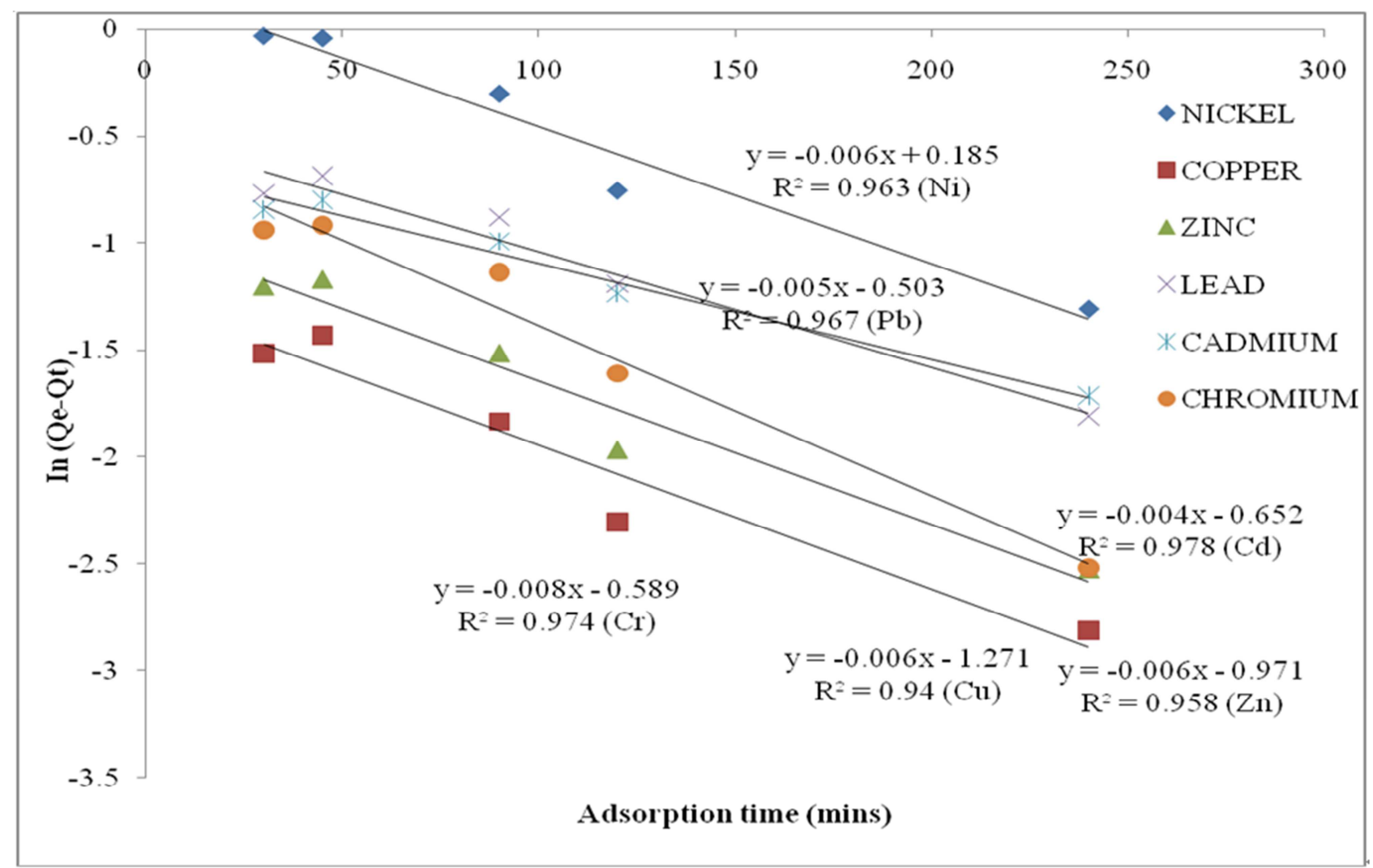

Fig. 1. The Pseudo First Order Kinetic Model for Multiple Adsorption of Heavy Metal Ions in Solution using Activated Carbon from Nigerian Bamboo (Initial Metallic Salt Concentration of $167 \mathrm{mg} / \mathrm{L}$ ). 


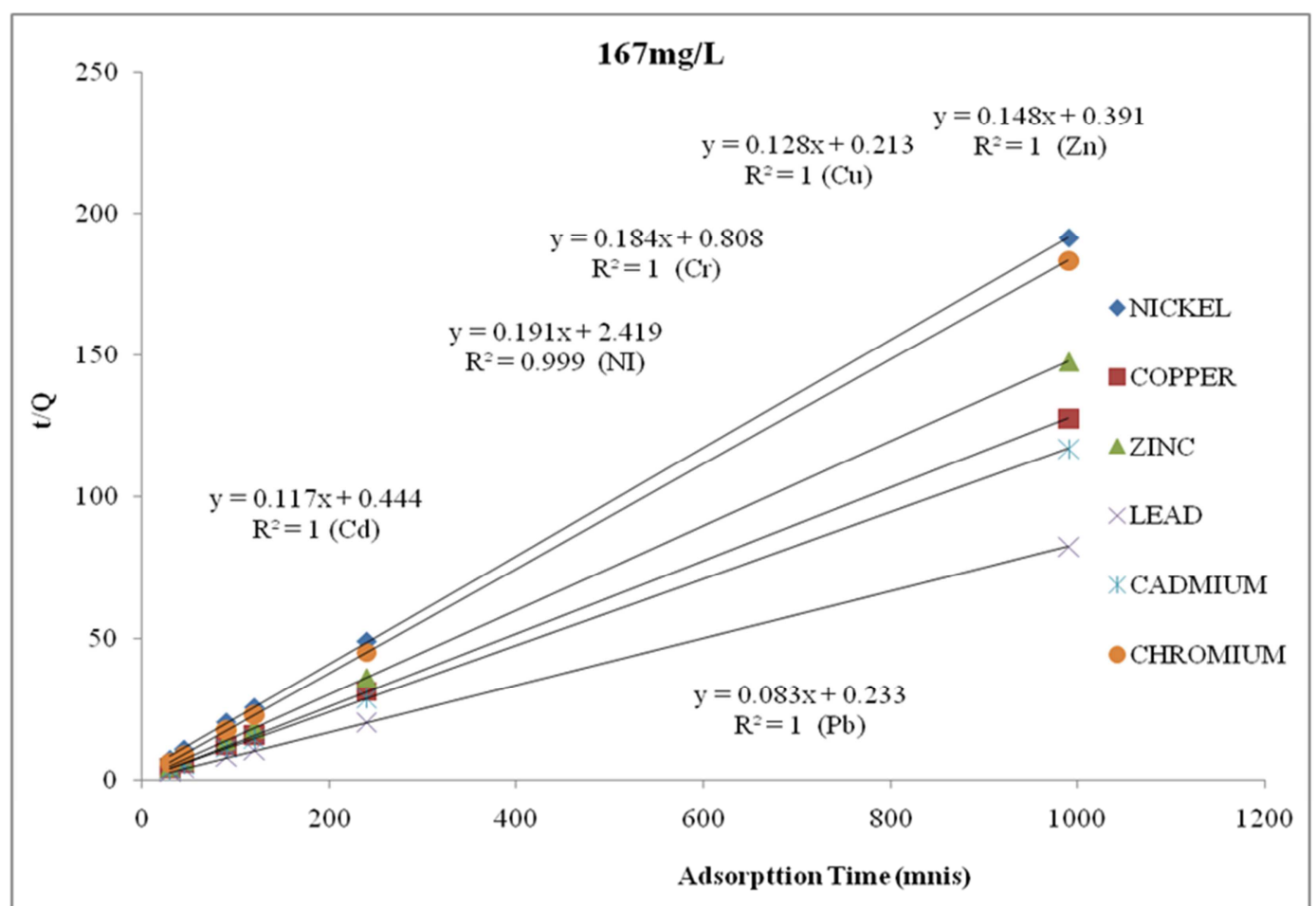

Fig. 2. The Pseudo Second Order Kinetic Model for Multiple Adsorption of Heavy Metal Ions in Solution using Activated Carbon from Nigerian Bamboo (Initial Metallic Salt Concentration of $167 \mathrm{mg} / \mathrm{L}$ ).

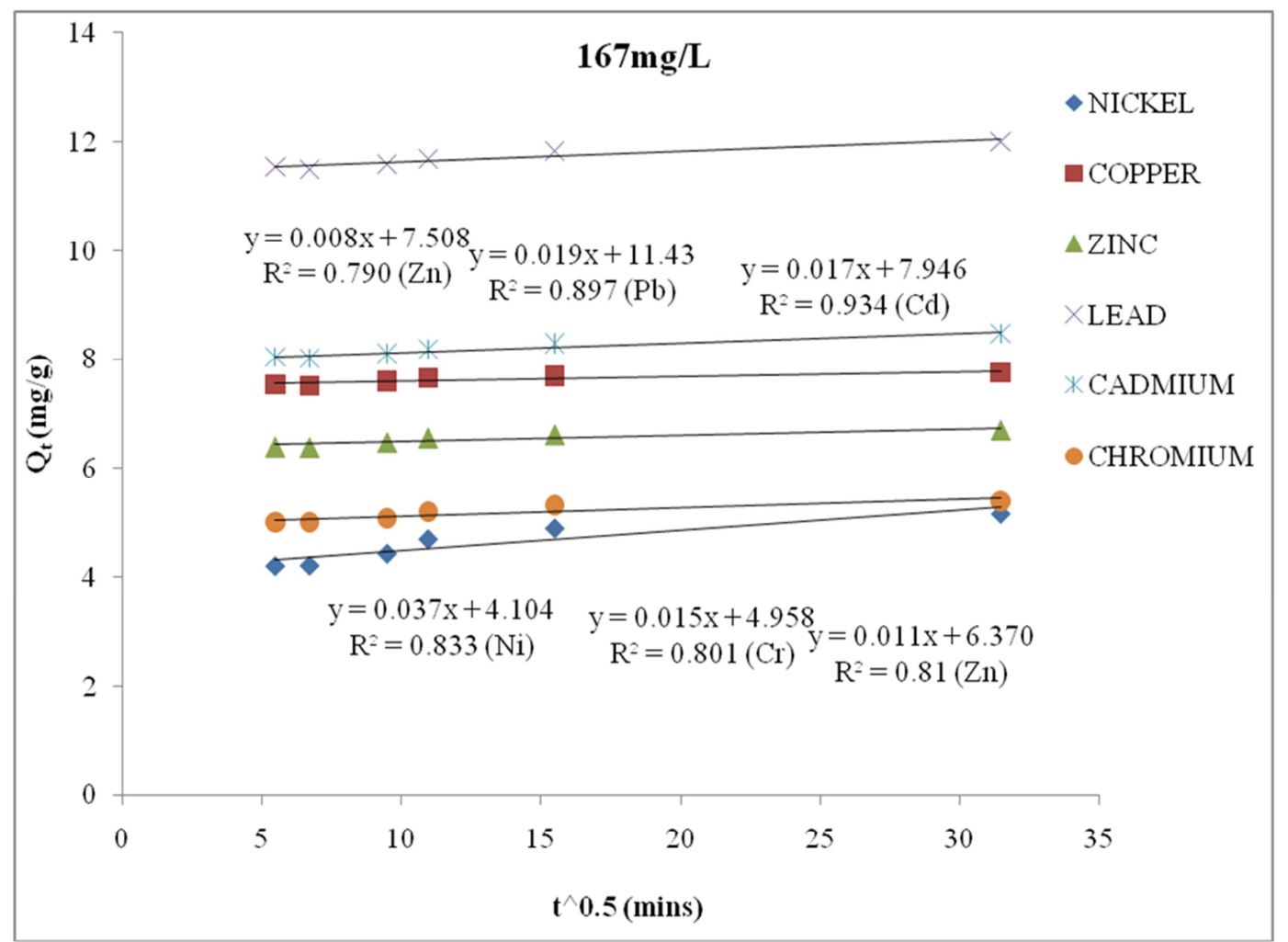

Fig. 3. Intraparticle diffusion kinetics for Multiple Adsorption of Heavy Metal Ions in Solution using Activated Carbon from Nigerian Bamboo (Initial Metallic Salt Concentration of $167 \mathrm{mg} / \mathrm{L}$.

The kinetics plots in Fig 1-3 were also carried out at different initial concentrations of the six metals in same aqueous solution. Table 1 shows the experimental and calculated amount of multiple heavy metal ions adsorbed using Nigerian Bamboo for pseudo first kinetic model, pseudo second order kinetic model and the intraparticle diffusion model at different initial concentrations. The firstorder rate constant $\mathrm{k}_{1}$ and the amount of heavy metal ions 
adsorbed at equilibrium from the model were calculated from the intercept and slope of the plot and are listed in Table 1. The pseudo first-order model did not fit well. It was found that the calculated $\mathrm{q}_{\mathrm{e}}$ values do not agree with the experimental $\mathrm{q}_{\mathrm{e}}$ values at all concentrations. Also there is no significant difference between the rate constant $\mathrm{k}_{1}$ for the heavy metal ions adsorbed at same initial concentrations compared with $\mathrm{k}_{2}$ in Table 1 . Hence the multiple sorption of these metal ions in same aqueous solution cannot be predicted using pseudo first kinetic model.

The calculated value of qe and the rate contants $k_{2}$ and $k_{d}$ for pseudo second order kinetic and the intra particle diffusion models were obtained from the slope and intercept of Figures 1, 2 and 3 and other plots at higher initial heavy metal ions concentrations. The experimental and calculated amount of multiple heavy metal ions adsorbed qe using
Nigerian Bamboo are in good agreement from Table 1 for pseudo second order kinetic model and the intraparticle diffusion model at different initial concentrations. The sorption data fitted well into the pseudo second order kinetic model than the intraparticle diffusion model at different initial concentrations with correlation coefficients of $\mathrm{R}^{2}=1$. The values of the rate constant $k_{2}$ and $k_{d}$ from the pseudo second order kinetic model and the intraparticle diffusion model differ significantly than the values of rate constant $k_{1}$ in pseudo first order kinetic model for all concentrations. For a solid - liquid sorption process, the solute transfer is usually characterized by either external mass transfer (boundary layer diffusion) or intraparticle diffusion or both. Therefore, the pseudo second-order model better represents the sorption kinetics of multiple adsorption of heavy metal ions in same aqueous solution using Nigerian Bamboo activated carbon.

Table 1. Experimental and Calculated Amount of Multiple Heavy Metal Ions Adsorbed Using Nigerian Bamboo for Pseudo first and Second Order Kinetic Model and the Intraparticle Diffusion Model at Different Initial Concentrations.

\begin{tabular}{|c|c|c|c|c|c|c|c|c|c|c|c|}
\hline \multirow{2}{*}{$\begin{array}{l}\text { Concentration of } \\
\text { metallic salt initially in } \\
\text { solution }\end{array}$} & \multirow{2}{*}{$\begin{array}{l}\text { Heavy metal } \\
\text { ions in } \\
\text { adsorbate }\end{array}$} & \multirow{2}{*}{$\begin{array}{l}\text { qe (Expt) } \\
\mathrm{mg} / \mathrm{g}\end{array}$} & \multicolumn{3}{|c|}{$\begin{array}{l}\text { Pseudo Second Order } \\
\text { kinetics Model }\end{array}$} & \multicolumn{3}{|c|}{ Intraparticle diffusion model } & \multicolumn{3}{|c|}{$\begin{array}{l}\text { Pseudo first Order kinetics } \\
\text { Model }\end{array}$} \\
\hline & & & qe (cal) $\mathrm{mg} / \mathrm{g}$ & $\mathbf{k}_{2}$ & $\mathbf{R}^{2}$ & qe (cal) mg/g & $\mathbf{k}_{\mathbf{d}}$ & $\mathbf{R}^{2}$ & qe (cal) $\mathrm{mg} / \mathrm{g}$ & $\mathbf{k}_{1}$ & $\mathbf{R}^{2}$ \\
\hline \multirow{7}{*}{$167 \mathrm{mg} / \mathrm{L}$} & $\mathrm{Ni}$ & 5.167 & 5.236 & 0.015 & 0.99 & 5.268 & 0.037 & 0.833 & 1.203 & 0.006 & 0.963 \\
\hline & $\mathrm{Cu}$ & 7.7533 & 7.813 & 0.077 & 1 & 7.760 & 0.008 & 0.790 & 0.281 & 0.006 & 0.940 \\
\hline & $\mathrm{Zn}$ & 6.7 & 6.757 & 0.056 & 1 & 6.716 & 0.011 & 0.810 & 0.379 & 0.006 & 0.958 \\
\hline & $\mathrm{Pb}$ & 12.01 & 12.048 & 0.030 & 1 & 12.028 & 0.019 & 0.897 & 0.553 & 0.005 & 0.967 \\
\hline & $\mathrm{Cd}$ & 8.46 & 8.547 & 0.031 & 1 & 8.481 & 0.017 & 0.934 & 0.521 & 0.008 & 0.978 \\
\hline & $\mathrm{Cr}$ & 5.396667 & 5.435 & 0.042 & 1 & 5.430 & 0.015 & 0.801 & 0.555 & 0.004 & 0.974 \\
\hline & & Qe (Expt) & qe (cal) $\mathrm{mg} / \mathrm{g}$ & $\mathrm{k}_{2}$ & $\mathrm{R}^{2}$ & qe (cal) $\mathrm{mg} / \mathrm{g}$ & $\mathrm{k}_{\mathrm{d}}$ & $\mathrm{R}^{2}$ & qe (cal) $\mathrm{mg} / \mathrm{g}$ & $\mathrm{k}_{1}$ & $\mathrm{R}^{2}$ \\
\hline \multirow{6}{*}{$333 \mathrm{mg} / 1$} & $\mathrm{Ni}$ & 10.2833 & 10.30928 & 0.0378 & 1 & 10.282 & 0.013 & 0.926 & 0.399 & 0.003 & 0.884 \\
\hline & $\mathrm{Cu}$ & 15.55667 & 15.625 & 0.0427 & 1 & 15.5805 & 0.014 & 0.868 & 0.455 & 0.005 & 0.957 \\
\hline & $\mathrm{Zn}$ & 13.38 & 13.51351 & 0.0373 & 1 & 13.369 & 0.013 & 0.932 & 0.410 & 0.004 & 0.910 \\
\hline & $\mathrm{Pb}$ & 24.01333 & 24.39024 & 0.0165 & 1 & 24.093 & 0.036 & 0.872 & 0.832 & 0.006 & 0.978 \\
\hline & $\mathrm{Cd}$ & 16.90667 & 16.94915 & 0.0288 & 1 & 16.928 & 0.019 & 0.927 & 0.590 & 0.004 & 0.973 \\
\hline & $\mathrm{Cr}$ & 10.83333 & 10.86957 & 0.0292 & 1 & 10.894 & 0.023 & 0.791 & 0.807 & 0.008 & 0.988 \\
\hline \multirow{7}{*}{$500 \mathrm{mg} / 1$} & & Qe (Expt) & qe (cal) $\mathrm{mg} / \mathrm{g}$ & $\mathrm{k}_{2}$ & $\mathrm{R}^{2}$ & qe (cal) $\mathrm{mg} / \mathrm{g}$ & $\mathrm{k}_{\mathrm{d}}$ & $\mathrm{R}^{2}$ & qe (cal) $\mathrm{mg} / \mathrm{g}$ & $\mathrm{k}_{1}$ & $\mathrm{R}^{2}$ \\
\hline & $\mathrm{Ni}$ & 15.42 & 15.625 & 0.027 & 1 & 15.439 & 0.020 & 0.904 & 0.650 & 0.005 & 0.972 \\
\hline & $\mathrm{Cu}$ & 23.34 & 23.810 & 0.038 & 1 & 23.341 & 0.014 & 0.859 & 0.485 & 0.005 & 0.911 \\
\hline & $\mathrm{Zn}$ & 20.04 & 20.408 & 0.036 & 1 & 20.073 & 0.016 & 0.887 & 0.515 & 0.005 & 0.965 \\
\hline & $\mathrm{Pb}$ & 35.75 & 37.037 & 0.012 & 1 & 35.754 & 0.037 & 0.612 & 1.073 & 0.005 & 0.980 \\
\hline & $\mathrm{Cd}$ & 23.74 & 23.810 & 0.016 & 1 & 23.791 & 0.035 & 0.904 & 1.113 & 0.005 & 0.989 \\
\hline & $\mathrm{Cr}$ & 15.36 & 15.385 & 0.075 & 1 & 15.362 & 0.008 & 0.754 & 0.302 & 0.007 & 0.905 \\
\hline
\end{tabular}

\subsection{Design of Adsorber for Removal of Multiple Heavy Metal Ions Using Activated Carbon from Nigerian Bamboo}

Fig 4 is a schematic diagram of a single stage batch adsorber. The adsorber is to simultaneously reduce the concentration of six heavy metals (often found in refinery and industrial waste waters) from initial concentration $\mathrm{C}_{\mathrm{o}}$ $(\mathrm{mg} / \mathrm{L})$ to final concentration $\mathrm{C}_{1}(\mathrm{mg} / \mathrm{L}) . \mathrm{M}(\mathrm{g})$ is the mass of activated carbon produced from Nigerian Bamboo added to the solution. The amount of the six heavy metals adsorbed initially $Q_{0}=0(\mathrm{mg} / \mathrm{g})$ and final amount of metal ions adsorbed is $\mathrm{Q}_{1}(\mathrm{mg} / \mathrm{g})$.

Overall material balance of Heavy metals ions for single stage adsorption is

$$
\mathrm{V}\left(\mathrm{C}_{\mathrm{o}}-\mathrm{C}_{1}\right)=\mathrm{M}\left(\mathrm{Q}_{1}-\mathrm{Q}_{\mathrm{o}}\right)
$$

At equilibrium conditions, $C_{1} \rightarrow \mathrm{C}_{\mathrm{e}}$ and $\mathrm{Q}_{1} \rightarrow \mathrm{Q}_{\mathrm{e}}$, Hence equation (5 ) becomes

$$
\mathrm{VC}_{\mathrm{o}}+\mathrm{MQ}_{\mathrm{o}}=\mathrm{VC}_{\mathrm{e}}+\mathrm{MQ}_{\mathrm{e}}
$$

Assume that there was no heavy metal ions adsorbed initially by the activated carbon i.e $\mathrm{Q}_{\mathrm{o}}=0$.

Hence equation 6 reduce to equation 7

$$
\frac{M}{V}=\frac{C_{o}-C_{e}}{Q_{e}}
$$

From previous works carried out by Ademiluyi and Nze (2016), Freundlich isotherm fitted best to experimental data.

Equation 7, therefore becomes

$$
\frac{M}{V}=\frac{C_{o}-C_{e}}{K C_{e}^{1 / n}}
$$


Qo, mass of solute ( $\mathrm{mg}) / \mathrm{g}$ of adsorbent

M, Mass of adsorbent ( $\mathrm{g}$ )

$\mathrm{C}_{\mathrm{o}}$, (mg of solute/Volume of

V, Volume of solute (L)

\section{solution, L)}

V, Volume of solute (L)

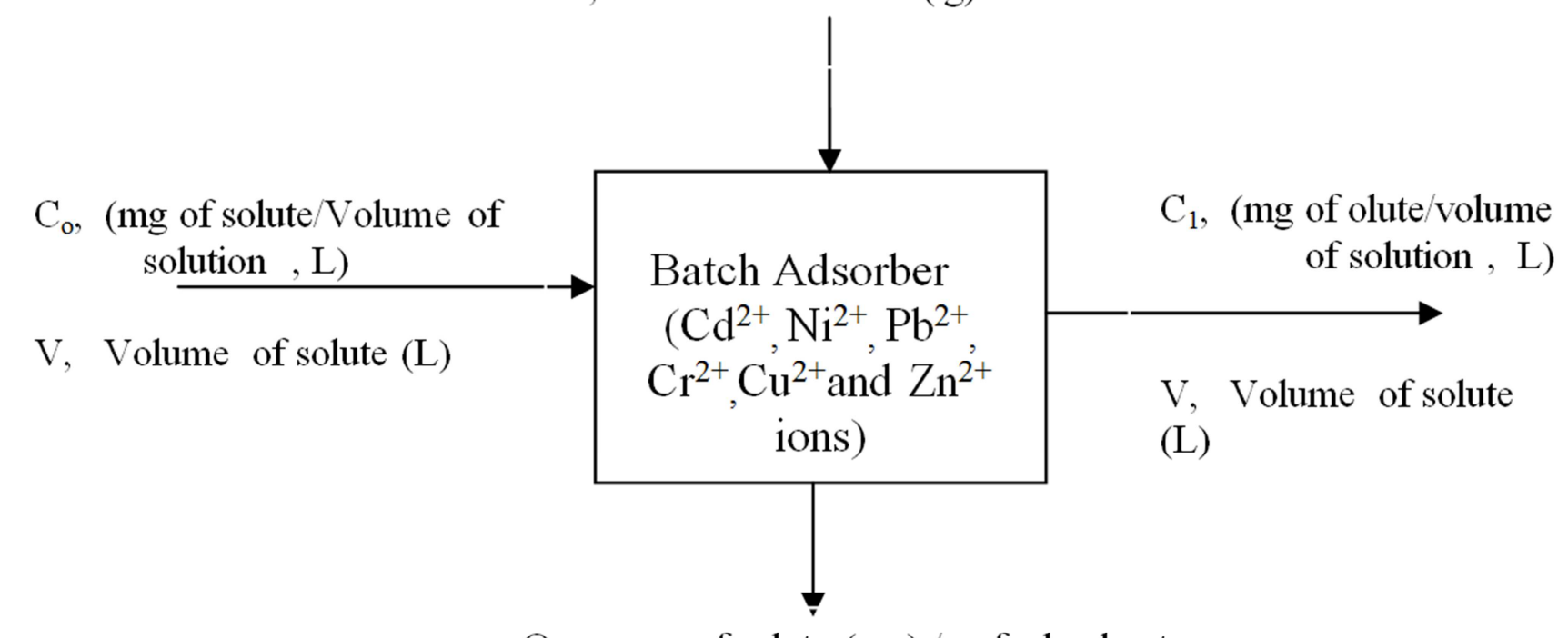

$\mathrm{Q}_{1}$, mass of solute $(\mathrm{mg}) / \mathrm{g}$ of adsorbent
$\mathrm{M}$, Mass of adsorbent $(\mathrm{g})$

Fig. 4. A Single Stage Batch Adsorber.

Since the treatment is for multiple heavy metal ions adsorption in same aqueous solution, we take a component balance for each metal ions in solution using pseudocomponent approach, so that equation (8) can be rewritten as:

$$
\frac{M}{V}=\frac{\sum C_{o i} x_{o i}-\sum C_{e i} x_{e i}}{\sum k_{i} C_{e i}^{1 / n_{i}} x_{e i}}
$$

where $\mathrm{x}_{\mathrm{oi}}$ is the mass fraction of each metal ions simultaneous in solution initially and $\mathrm{x}_{\mathrm{ei}}$ is the final mass fraction of each metal ions simultaneous adsorbed in solution at equilibrium, the values of $\mathrm{k}$ and $\mathrm{n}$ for each metal ions adsorbed were obtained from the work done by Ademiluyi and Eze [11] in Table 2.

Table 2. Freundlich, Temkin constants related to multiple adsorption of different metal ions from aqueous solution using activated carbon from Nigerian Bamboo.

\begin{tabular}{|c|c|c|c|c|c|c|c|}
\hline \multirow{2}{*}{ Heavy metal ions adsorbed } & \multicolumn{3}{|c|}{ Freundlich Isotherm } & \multicolumn{4}{|c|}{ Temkin Isotherm } \\
\hline & $\mathbf{K}_{\mathbf{i}}$ & $\mathbf{n}_{\mathbf{i}}$ & $\mathbf{R}^{2}$ & $\mathbf{A}$ & B & $b=R T / B$ & $\mathbf{R}^{2}$ \\
\hline Nickel & 0.479 & 1.035 & 0.995 & 0.143 & 8.89 & 281.498 & 0.958 \\
\hline Copper & 5.578 & 0.799 & 0.978 & 1.134 & 17.52 & 142.838 & 0.955 \\
\hline Zinc & 11.98 & 1.536 & 0.939 & 5.004 & 7.999 & 312.853 & 0.952 \\
\hline Lead & 3.658 & 1.157 & 0.985 & 0.439 & 18.88 & 132.548 & 0.99 \\
\hline Cadmium & 4.167 & 1.919 & 0.909 & 0.638 & 7.969 & 314.031 & 0.97 \\
\hline Chromium & 10.01 & 0.710 & 0.956 & 2.116 & 14.42 & 173.545 & 0.974 \\
\hline
\end{tabular}

source: Ademiluyi and Nze [11]

The Mass of adsorbent was then calculated using equation 9 , by varying the volume of adsorbate $\left(10-100 \mathrm{~m}^{3}\right)$ used for waste water treated containing various percentage of heavy metal ions simultaneously removed at initial adsorbate concentration of $50 \mathrm{mg} / \mathrm{L}$. The amount of adsorbent required increases as the percentage metal ion removal increases. Can et al., [15] had similar results during the adsorption of rhodium (III) ions onto gallic acid formaldehyde resin in a batch adsorber. The mass of adsorbent required (M) was then plotted against volume of waste water or effluent treated as shown in Fig 5. Therefore, the amount of Nigerian bamboo activated bamboo required to simultaneously remove $99 \%$ of these heavy metal ions in same batch adsorber with initial concentration of $50 \mathrm{mg} / \mathrm{L}$ from Figure 5 was $1100 \mathrm{~g}, 1257$, $1414 \mathrm{~g}$ and $1571 \mathrm{~g}$ for adsorbate volume of $70 \mathrm{~m}^{3}, 80 \mathrm{~m}^{3}$, $90 \mathrm{~m}^{3}, 100 \mathrm{~m}^{3}$ respectively. 


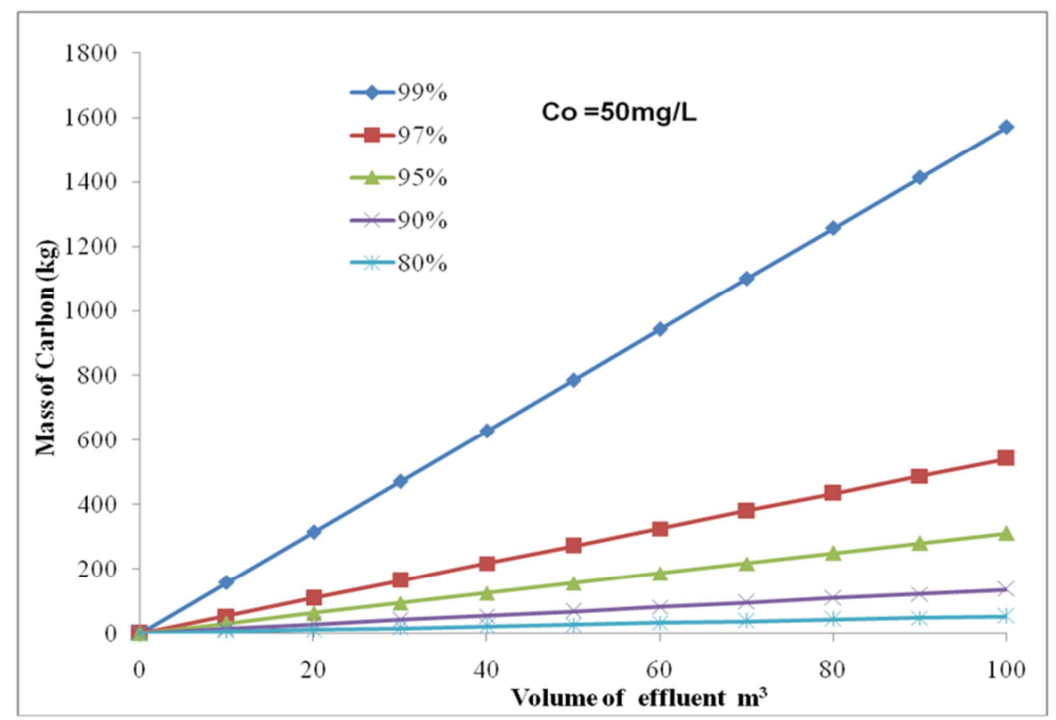

Fig. 5. The mass of adsorbent required (M) against volume of effluent treated at initial heavy metal ions concentration of 50mg/L at various percentage multiheavy metal ion removal.

The equations developed for designing adsorber for the multiple removal of heavy metal ions in waste waters in this study was based on the permissible heavy metal ions concentration of effluent as specified by World Health organization WHO to be discharge after treatment in any by industries or refineries for these six heavy metal ions in solution as shown in Table 3. This shows that percentage metal ions that should be removed from waste water should be about $97-99 \%$. Hence the amount of adsorbent needed for adsorber design was based on $99 \%$ removal efficiency. The mass of Bamboo adsorbent required (M) against initial heavy metal concentration $\left(\mathrm{C}_{\mathrm{o}} \mathrm{mg} / \mathrm{L}\right)$ at different volume of solutions treated for $99 \%$ heavy metal ions removed is shown in Fig 6.
Table 3. WHO Standard for Permissible Heavy Metal Ions Concentration in Waste Water before discharge.

\begin{tabular}{lll}
\hline $\begin{array}{l}\text { Heavy metal } \\
\text { ions }\end{array}$ & $\begin{array}{l}\text { *Amount in Effluent } \\
(\mathbf{m g} / \mathbf{L})\end{array}$ & $\begin{array}{l}\text { \% metal ions that should be } \\
\text { removed }\end{array}$ \\
\hline NICKEL & 0.02 & 99.98 \\
COPPER & 2 & 98 \\
ZINC & 3 & 97 \\
LEAD & 0.01 & 99.99 \\
CADMIUM & 0.003 & 99.997 \\
CHROMIUM & 0.05 & 99.95 \\
\hline
\end{tabular}

*source: WHO [14]

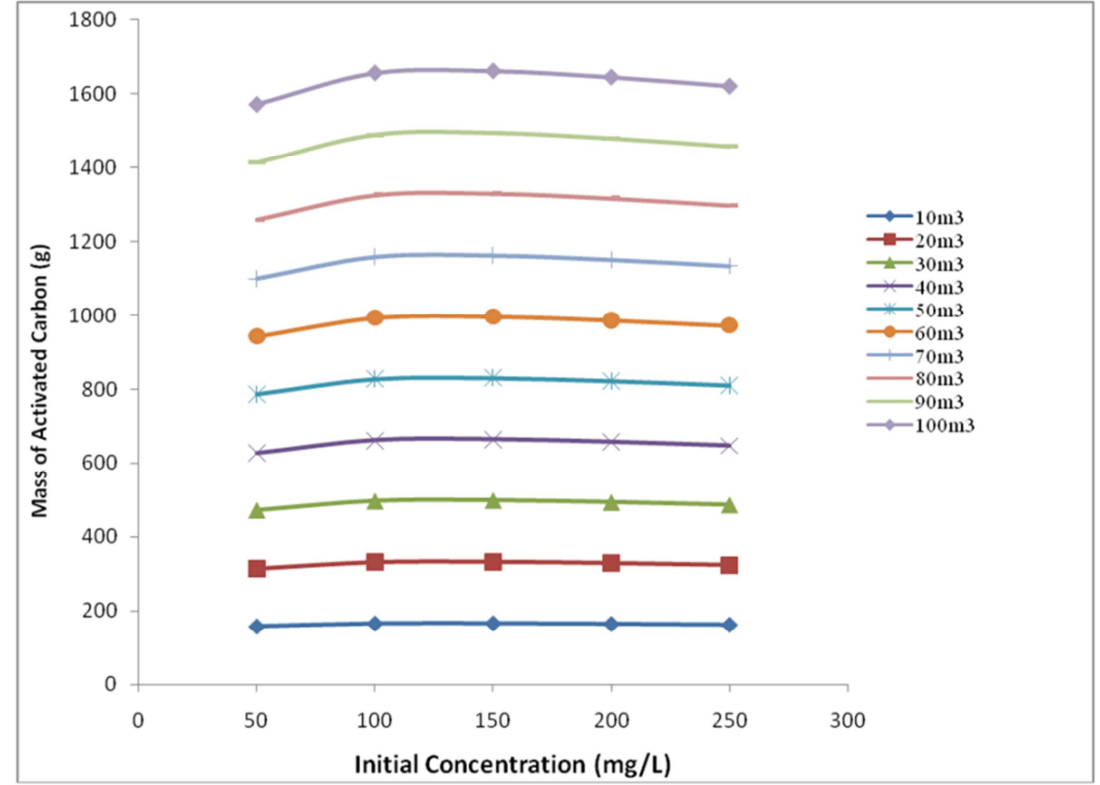

Fig. 6. The mass of Nigerian Bamboo adsorbent required $(M)$ against initial heavy metal concentration $\left(C_{o} m g / L\right)$ at different volume of solutions treated for 99\% multi-heavy metal ions removal. 
The mass of adsorbent needed can be predicted from the result obtained from Figure 6. The volume of solution to be treated will now be used to calculate how many batch adsorber will be required to remove $99 \%$ of the heavy metals simultaneously using activated carbon from Nigerian Bamboo.

\subsection{Determination of Number of Adsorption Stages Required With Time}

Overall material balance of Heavy metals ions for single stage adsorption from equation 5 can be written for $n$ stages to obtain equation (10).

$$
\mathrm{V}\left(\mathrm{C}_{\mathrm{n}-1}-\mathrm{C}_{\mathrm{n}}\right)=\mathrm{M}\left(\mathrm{Q}_{\mathrm{n}}-\mathrm{Q}_{\mathrm{o}}\right)
$$

The value of $Q_{n}$ in equation 10 will be obtained from the Pseudo Second order kinetic model for adsorption of heavy metal ions from equation (3) since pseudo second order kinetic model fitted the experimental data well better than pseudo first order kinetic model and the intraparticle diffusion model as in shown in Table 1.

Hence writing equation 3 in terms of $Q_{t}$ since $Q_{n}$ with time is $Q_{t}$ gives equation 11:

$$
Q_{t}=\frac{t k_{2} Q_{e}^{2}}{1+t k_{2} Q_{e}}
$$

Since fresh adsorbents are used at each stage $\left(Q_{0}=0\right)$ and the pseudo-second order kinetic model is used to describe equilibrium in the two-stage sorption system, then the mass balance equation can be obtained for $\mathrm{n}$ number of stages as equation (12) by combining equations (10) and (11) to give:

$$
C_{n-1}-C_{n}=\frac{M\left(k_{2}\right)_{n} t\left(Q_{e}^{2}\right)_{n}}{V\left(1+t\left(k_{2}\right)_{n}\left(Q_{e}\right)_{n}\right)}
$$

The total amount of heavy metal ion removed can be calculated analytically as follows:

$$
\sum_{n=1}^{m} C_{n-1}-C_{n}=\sum_{n=1}^{m} \frac{M\left(k_{2}\right)_{n} t\left(Q_{e}^{2}\right)_{n}}{V\left(1+t\left(k_{2}\right)_{n}\left(Q_{e}\right)_{n}\right)}
$$

Where $\mathrm{n}$ is the adsorption system number $(\mathrm{n}=1,2$, $3 . . ., \ldots, \ldots, \mathrm{m})$.

The amount of heavy metal ion removed $R_{n}$ from each stage can be obtained from equation 14 as:

$$
R_{n}=\frac{100\left(C_{n-1}-C_{n}\right)}{C_{o}}=\frac{100 M\left(k_{2}\right)_{n} t\left(Q_{e}^{2}\right)_{n}}{V C_{o}\left(1+t\left(k_{2}\right)_{n}\left(Q_{e}\right)_{n}\right)}
$$

So that the total amount of heavy metal ion removed can be obtained from equation 16 as:

$$
\sum_{n=1}^{m} R_{n}=\frac{M}{V} \sum_{n=1}^{m} \frac{100 t\left(k_{2}\right)_{n}\left(Q_{e}^{2}\right)_{n}}{C_{o}\left[1+t\left(k_{2}\right)_{n}\left(Q_{e}\right)_{n}\right]}
$$

The adsorption carried out in this work is for simultaneous multiple heavy metal ions adsorption of six metal ions in same aqueous solution hence, component balance taken for each metal ions in solution using pseudo-component approach gives equation (16) by rewritten 15 as:

$$
\sum_{n=1}^{m} R_{n i}=\frac{M}{V} \sum_{n=1}^{m} \frac{100 t\left(k_{2 i}\right)_{n}\left(Q_{e i}^{2}\right)_{n}}{C_{o i}\left[1+t\left(k_{2 i}\right)_{n}\left(Q_{e i}\right)_{n}\right]}
$$

Where $R_{n i}$ is the amount of heavy metal ion removed for each metal ion $\mathrm{i}$ in solution. Also the amount of heavy metal ion adsorbed $\mathrm{Q}_{\mathrm{e}}$ also changes with initial concentration of each heavy metal ion in solution hence, expressing $Q_{e}$ and $k_{2}$ as a function of $C_{\mathrm{o}}$ gives equation 17 and 18 .

$$
\begin{gathered}
Q_{e}=A_{q} C_{o}^{B_{q}} \\
k_{2}=A_{k} C_{o}^{B_{k}}
\end{gathered}
$$

So that the corresponding linear plots of the values of $\mathrm{Q}_{e}$ and $k_{2}$ in Table 2 against initial heavy metal ions concentration $C_{\mathrm{o}}$, were regressed to obtain expressions for these values in terms of the initial heavy metal ions concentration.

Substituting the equation 17 and 18 into equation 16 gives equation 19

$$
\sum_{n=1}^{n} R_{n i}=\frac{M}{V} \sum_{n=1}^{n} \frac{100 t\left(A_{k i} C_{o i}^{B_{k I}}\right)_{n}\left(\left(A_{q i} C_{o i}^{B_{q i}}\right)^{2}\right)_{n}\left[1+t\left(A_{k i} C_{o i}^{B_{k i}}\right)_{n}\left(A_{q i} C_{o i}^{B_{q i}}\right)_{n}\right]}{C_{o}[1}
$$

The total amount of heavy metal removed for each metal ion in solution can now be calculated for using equation 19 at every stage. The values of $\mathrm{Q}_{\mathrm{ei}}$ and $\mathrm{K}_{2 \mathrm{i}}$ in equation 17 changes with changes in the initial concentrations $\mathrm{C}_{\mathrm{oi}}$ of each heavy metal ion in same aqueous solution. Equations (9) and (19) can then be used for predicting the removal of multiple heavy metal ions at any given initial heavy metal ions concentration and the reaction time for any multi-stage adsorption system.

The Empirical parameters for prediction of $Q_{e}$ and $\mathrm{k}_{2}$ for different initial heavy metal ion concentration $C_{0}$ is presented in Table 4 . The validity of these values is revealed from the high correlation coefficients $\mathrm{R}^{2}$ obtained as shown in Table 4. 
Table 4. Empirical parameters for prediction of Qe and $k_{2}$ for different initial heavy metal ion concentration $C_{0}$.

\begin{tabular}{lllllll}
\hline Name of Heavy metal ions & $\mathbf{A}_{\mathbf{q}}$ & $\mathbf{B}_{\mathbf{q}}$ & $\mathbf{R}^{\mathbf{2}}$ & $\mathbf{A}_{\mathbf{k}}$ & $\mathbf{B}_{\mathbf{k}}$ & $\mathbf{R}^{\mathbf{2}}$ \\
\hline NICKEL & 0.086 & 0.989 & 0.999 & 0.909 & -0.65 & 0.999 \\
COPPER & 0.094 & 1.01 & 0.999 & 1.211 & -0.63 & 0.99 \\
ZINC & 0.097 & 1.005 & 1.000 & 0.312 & -0.40 & 0.999 \\
LEAD & 0.087 & 1.022 & 1.000 & 1.492 & -0.81 & 0.989 \\
CADMIUM & 0.125 & 0.941 & 0.998 & 0.325 & -0.52 & 0.944 \\
CHROMIUM & 0.12 & 0.953 & 0.998 & 0.366 & -0.54 & 0.998 \\
\hline
\end{tabular}

\section{Conclusion}

The kinetics modeling for design of adsorber for multiple adsorption of heavy metal ions was carried out using activated carbon from waste Nigerian bamboo. In order to determine the mechanism of sorption of multiple adsorption of these heavy metals ions, the kinetic data were modeled using the pseudo first order, pseudo second order kinetic equations, and intra-particle diffusion models. The pseudo first order did not fit well into the kinetic data. The pseudo second order equation was the best applicable model to describe the sorption process. Hence the pseudo second order kinetic reaction is the rate controlling step with some intra particle diffusion taking place. An empirical model was also developed which can then be used for predicting and designing adsorber for the multiple removal of $99 \%$ heavy metal ions at any given initial heavy metal ions concentration and the adsorption time required for any multi-stage adsorption system using Nigerian Bamboo activated carbon.

\section{References}

[1] A. Sharafian, S. M. N. Mehr, W. Huttema and M. Bahrami "Effects of different adsorber bed designs on in-situ water uptake rate measurements of AQSOA FAM-Z02 for vehicle air conditioning applications" Applied Thermal Engineering, Vol. 98, Issue 5, pp 568-574, (2016).

[2] S. Debnath, A. Maity, and K. Pillay "Magnetic chitosan-GO nanocomposite: Synthesis, characterization and batch adsorber design for $\mathrm{Cr}(\mathrm{VI})$ removal" Journal of Environmental Chemical Engineering, Vol. 2, Issue 2, pp 963-973, (2014)

[3] U. John, K. Oubagaranadin and Z. V. P. Murthy "Isotherm modeling and batch adsorber design for the adsorption of $\mathrm{Cu}(\mathrm{II})$ on a clay containing montmorillonite" Applied Clay Science, Vol 50, Issue 3, pp 409-413, (2010).

[4] D. Pirozzi, and F Sannino "Design of a multi-stage stirred adsorber using mesoporous metal oxides for herbicide removal from wastewaters" Journal of Environmental Chemical Engineering, Vol. 2 Issue 1, pp 211-219, (2014).

[5] E. Vunain, A. K Mishra' and B. B Mamba "Dendrimers, mesoporous silicas and chitosan-based nanosorbents for the removal of heavy-metal ions: A review" International Journal of Biological Macromolecules, Vol. 86, pp 570-586, (2016).

[6] K. Kadirvelu, M. Kavipriya, C. Karthika, M. Radhika, N. Vennilamani, and S. Pattabhi "Utilization of various agricultural wastes for activated carbon preparation and application for the removal of dyes and metal ions from aqueous solution" Bioresource. Technology, Vol 87 pp. 129132, (2003).

[7] F. Ge, M. Li, H. Ye, and B. Zhao " Effective removal of heavy metal ions $\mathrm{Cd}^{2+}, \mathrm{Zn}^{2+}, \mathrm{Pb}^{2+}, \mathrm{Cu}^{2+}$ from aqueous solution by polymer-modified magnetic nanoparticles" J. of Hazardous Materials, Vol. 211-212, pp 366-372, (2012).

[8] J. Huang, Y. Cao, Z. Liu, Z. Deng, F. Tang, and W. Wang " Efficient removal of heavy metal ions from water system by titanate nanoflowers" Chem. Eng. Journal, Vol. 180, pp 75-80, (2012).

[9] I.G. Karthikeyan, S. Siva Ilango, "Equilibrium Sorption studies of $\mathrm{Fe}, \mathrm{Cu}$ and $\mathrm{Co}$ ions in aqueous medium using activated Carbon prepared from Recinius Communis Linn." J. Appl. Sci. Environ. Manage. Vol. 12 (2) 81-87, (2008).

[10] F. T Ademiluyi and J. C. Nze "Multiple Adsorption of Heavy Metal Ions in Aqueous Solution using Activated Carbon from Nigerian Bamboo", International Journal of Research in Engineering and Technology. 5 (1) 164-169, (2016a). Retrieved from: http://esatjournals.net/ijret/2016v05/i01/IJRET20160501033.p df.

[11] F. T Ademiluyi and J. C. Nze "Sorption Characteristics for Multiple Adsorption of Heavy Metal Ions Using Activated Carbon from Nigerian Bamboo", Journal of Materials Science and Chemical Engineering Vol 4, Issue 4, pp39-48 (2016b).

[12] F. T Ademiluyi and E. O David-West, "Effect of Chemical Activation on the Adsorption of Heavy Metals using Activated Carbons from Waste Materials", ISRN Chemical Engineering (2012): Retrieved from http://www.hindawi.com/isrn/Chemeng/2012/674209/.

[13] E.A Mehmet, S. Dursun, C. Ozdemir, and M. Karatas "Heavy metal adsorption by modified oak sawdust: Thermodynamics and kinetics" Journal of Hazardous Materials 141, pp 77-85, (2007).

[14] H. Zhenga, D. Liua, Y. Zhenga, S. Liang, Z. Liua, "Sorption isotherm and kinetic modeling of aniline on Cr-bentonite" Journal of Hazardous Materials Vol. 167, pp141-147, (2009).

[15] WHO “Guidelines for Drinking-water Quality" (1993) Retrieved from:

http://www.lenntech.com/applications/drinking/standards/who -s-drinking-water-standards.html.

[16] Can. M, Bulut. E, Örnek A. "A Batch Adsorber Design for Rhodium Adsorption on Gallic Acid Formaldehyde Resin" Acta Physica Polonica A, Vol. 127, pp 1311-1313 (2015). 